\title{
REFLECTION ESSAYS
}

Journal of Communication Pedagogy
COMMUNALA 019, Vol. 2, 76-82
OThe Author(s) 2019
PEDAGOGY

\section{Teaching Public Speaking Online-Not a Problem but an Opportunity!}

\author{
Sherwyn Morreale, Janice Thorpe, and Susan Ward
}

Keywords: online public speaking, online course design, online course delivery

\begin{abstract}
This reflection essay focuses on the problems inherent in the design and development of an online public speaking course, which in part result from presuming the course must mirror its face-to-face counterpart. Based on our own experiences and background in designing an online public speaking course, we recommend that instructors and administrators of this course solve such problems by employing design strategies that effectively adapt the course content and pedagogy to a digital context. The essay begins with a description of an integrated course design model (Fink, 2005) that proved useful to us for accomplishing this task. Then we discuss how we used the four components of the initial design stage of this model to take advantage of opportunities for teaching public speaking online.
\end{abstract}

While teaching public speaking online is a rather common practice, concerns about doing so often prompt instructors to consider lingering problems inherent in the design and development of the course (Allen, 2006; Corum, 2013; Hunt, 2012). Because the approach to designing this course presumes it must be taught in a way that mirrors the face-to-face course, such an approach fails to employ strategies that effectively adapt the course content and pedagogy to a digital context (Schwartzman, 2007). Based on our own experiences and background in designing an online public speaking course, we recommend solving this problem by using Fink's (2005) Integrated Course Design model.

Sherwyn Morreale and Janice Thorpe, University of Colorado Colorado Springs, Colorado Springs, CO

Susan Ward, Delaware County Community College, Media, PA

CONTACT: smorreal@uccs.edu 
To this end, this reflection essay first describes Fink's (2005) model and then moves to a discussion about how we applied the model to the design of our course. In so doing, it is our hope that instructors and administrators involved in one of Communication Studies' most popular basic courses (Morreale, Myers, Backlund, \& Simonds, 2015) will realize that considering the digital context within which the course is taught acts as a solid foundation for effective course design as well as fosters a favorable learning environment for students.

\section{Fink's Integrated Course Design Model}

Fink's (2005) Integrated Course Design model is based on the notion that good course design combines the components of instructional design into "a relational, integrated model rather than a linear one" (p. 1). The initial design phase proposed by Fink, which guided our course development and design, calls for examining four components: situational factors affecting any course, learning goals as the course foundation, teaching and learning activities, and feedback and assessment.

\section{Situational Factors Affecting Any Course}

Considering the context within which the course is situated is important as it assists with creating a significant learning experience for students. Fink (2005) identified five key situational factors: (a) the specific context of the teaching/learning situation, (b) the general context of the learning situation, (c) the nature of the subject, (d) learner characteristics, and (e) instructor characteristics. In addressing the specific context of the teaching/learning situation, the instructor should consider, in part, the delivery method of the course and the physical elements of the learning environment that affect the course. The general context of the learning situation addresses any learning expectations placed on the course by the institution, the department, or the profession. In terms of the nature of the subject, the issue is whether the subject is primarily theoretical, practical, or a combination of the two. When considering learner characteristics, instructors should reflect on the life situation of the learners; their prior knowledge, experiences, and initial feelings about the course; and their learning goals, expectations, and preferred learning styles. Instructor characteristics that should be examined include assessing instructors' attitudes toward the subject and the students, their strengths in teaching, and their level of knowledge and familiarity with the subject.

\section{Learning Goals as the Course Foundation}

The development of learning goals should be motivated by one question: "What would I like the impact of this course to be on students, 2-3 years after the course is over?" (Fink, 2005, p. 8). The answer to this question encourages creating specific learning objectives for any given course, as opposed to solely focusing on the topics that instructors would like to include and teach about in the course.

\section{Teaching and Learning Activities}

Describing the difference between passive and active learning, Fink (2005) noted that simply receiving information is passive learning (e.g., reading a textbook), whereas active learning requires students to participate in reflective dialogue with themselves and others as they engage in activities that ask them to do and observe. Fink proposed a holistic view of active learning, one that integrates receiving information with doing and observing activities. 


\section{Feedback and Assessment}

Fink (2005) encouraged the use of "educative assessment," which focuses on active learning and is beyond evaluation "designed solely to give the instructor a basis for awarding a grade" (p. 15). Feedback should be given as frequently as possible and delivered as immediately as possible; it also should be discriminating in that it makes clear the differences among poor, acceptable, and exceptional work while being delivered in an empathic manner. Instructors should provide clear guidelines for how students will be assessed, including the criteria used for assessment and feedback, as these criteria reveal instructor standards and answer the questions regarding what quality work looks like in the course.

\section{Design and Development of an Online Public Speaking Course}

Armed with an explanation of Fink's Integrated Course Design model, we now describe our application of the model's four components to the design and development of our online public speaking course. In doing so, we will note how the use of this model helped to effectively adapt the course content and pedagogy to a digital context.

\section{Situational Factors Affecting Our Course}

The specific context of our online public speaking course centers on a course that is taught completely online, synchronously and asynchronously, without mandatory or optional on-campus meetings. Some disciplinary controversy about this specific context revolves around whether the course can be taught online because of the importance of speaking to a live audience (Ward, 2016). This challenge was addressed by including both synchronous and asynchronous speaking opportunities in our course. For example, we used technology (e.g., Microsoft Teams) to facilitate students presenting in real time to small groups of their peers. Regarding the general context of the teaching/learning situation, we wrote and adapted departmental expectations and existing learning goals for the course, but included additional delivery competencies relevant to presenting with online technology.

In terms of the nature of the subject, the online public speaking course should, like its in-seat (face-toface) counterpart, be a blend of theory and practice. Students should learn about rhetorical strategies and how to apply these strategies in their presentations, whether in-seat or online. The design of our course emphasized an appropriate balance of content and application. For example, at the start of the course, students learned about the nature of public speaking and rhetorical competence, soon followed by substantive instruction about theories and models for speaking to inform and speaking to persuade.

Two learner characteristics were identified as most relevant. First, because many of our students take courses online for convenience, as their schedules do not allow them to come to campus, scheduling some speeches asynchronously addressed this characteristic, and engaging in clear communication at the start of the course about the synchronous requirements helped students to plan appropriately. Second, we recognized that some of our students may have public speaking anxiety, just as students do in any in-seat public speaking course. Given recent research demonstrating the potential for decreasing students' public speaking anxiety scores from the beginning to the end of an online public speaking course, we addressed anxiety within the first 2 weeks of our course (Westwick, Hunter, \& Haleta, 2015). This topic was specifically addressed in a discussion forum where students shared their experiences about anxiety with other students. 
Finally, the instructor characteristics that mattered most tended to relate to motivation or hesitancy about teaching public speaking online. Beebe and Mottet (2009) provided practical advice about teaching competently, which was applied to the challenges inherent in the use of online pedagogical technology (Morreale, 2015). While this list is not exhaustive, the usefulness of these six components of instructional communication competence are worth consideration by instructors of any online course (see Table 1).

Based on our experience, instructors in online public speaking courses can use these six components to enhance their delivery or presence during an online course in the following ways (Beebe \& Mottet, 2009).

1. Immediacy can be achieved nonverbally by looking directly at the students (i.e., the camera) and verbally using each student's first name when providing individual feedback.

2. A sense of affinity or liking can be communicated in all written communication with students, given it often is the primary form of feedback in a digital environment. During synchronous interactions, affinity behaviors should appropriately mirror those behaviors exhibited in an inseat course (e.g., facial expressions, warm tone of voice, eye contact).

3. Relational power in the online environment can result from the instructor communicating about course expectations and requirements assertively and with confidence, both verbally and in writing (e.g., phrasing of announcements, online descriptions of assignments, feedback about speech performances).

4. Credibility can be enhanced by instructors demonstrating their depth of knowledge of course content and appearing to make fair decisions in the best interest of all students equally.

5. Clarity can be demonstrated by speaking at a rate and intensity that is easily understood in the online environment. Written instructions should be precise and explicit in this environment.

6. Humor can be used spontaneously during online interactions and in written announcements, carefully, of course, and never offensively.

\begin{tabular}{|l|l|}
\hline \multicolumn{2}{|l|}{$\begin{array}{l}\text { TABLE } 1 \\
\text { Core Components of Instructional Competence (Beebe \& Mottet, 2009) }\end{array}$} \\
\hline Component & Description of the Component \\
\hline Immediacy & $\begin{array}{l}\text { The perception of physical and psychological closeness achieved } \\
\text { by communication behaviors that enhance the quality of verbal } \\
\text { and nonverbal interactions with another. }\end{array}$ \\
\hline Affinity-seeking & $\begin{array}{l}\text { Feelings of liking or attraction to the other person that result from } \\
\text { verbal and nonverbal behaviors, which are used to develop high } \\
\text { levels of attraction in a relationship. }\end{array}$ \\
\hline $\begin{array}{l}\text { Relational power (including behavior } \\
\text { alteration techniques) }\end{array}$ & $\begin{array}{l}\text { The ability to influence another person, either based on role or } \\
\text { position or being trusted and liked. }\end{array}$ \\
\hline Credibility & $\begin{array}{l}\text { The perception of character, intelligence, and goodwill a person } \\
\text { is deemed to possess. }\end{array}$ \\
\hline Clarity & $\begin{array}{l}\text { Speaking articulately and audibly, staying on task, and using } \\
\text { commonly understood vocabulary. }\end{array}$ \\
\hline Humor & $\begin{array}{l}\text { Humorous statements related to course material, nonverbal } \\
\text { behaviors, humorous props, sarcasm, and unintentional humor. }\end{array}$ \\
\hline
\end{tabular}




\section{Learning Goals for Our Course}

Collaboration with other faculty members in our department and in the Communication discipline led us to create a set of learning goals centered not only on equipping students to speak competently in digital contexts, but also-and equally important—on being able to transfer their newly acquired public speaking skills to other out-of-class digital and non-digital contexts. This skills transfer was facilitated by the pedagogical and evaluative use of the eight public speaking competencies, outlined in the Competent Public Speaker form available from the National Communication Association (NCA), which are not specific to any particular speaking context (Morreale, Moore, Surges-Tatum, \& Webster, 2007) (see Table 2). We also decided to use Spitzberg's (2000) model of communication competence as the foundation for developing the course learning objectives. This model identifies three components of competent communication (i.e., motivation, knowledge, and skills) that interact to result in appropriate and effective communication in most communication situations, including public speaking in a digital environment.

\section{Teaching and Learning Activities Based on Learning Goals \\ Motivation}

To address the motivation (i.e., affect) component of Spitzberg's (2000) model, students participated in an online discussion forum to discuss public speaking anxiety in an online environment as opposed to a face-to-face offline environment. To help manage anxiety behaviorally in a variety of situations, some speaking assignments required students to deliver speeches live (but online) to a group of their peers, which allowed them to provide immediate feedback to one another.

\section{Knowledge}

Students initially met the knowledge component by viewing a professionally produced 10-part video series that included exemplary informative and persuasive speeches and a presentation by our two course instructors of the NCA eight public speaking competencies. (Free access to this video series is available at https://www.uccs.edu/comm/courses/comm-3190.) A follow-up assignment required students to reflect on, and apply, the eight public speaking competencies by contrasting a poor speech with an exemplary speech.

\section{TABLE 2}

Eight Public Speaking Competencies (Morreale, Moore, Surges-Tatum, \& Webster, 2007)

\section{Component}

1. Chooses and narrows a topic appropriately for the audience and occasion.

2. Communicates the thesis/specific purpose in a manner appropriate for the audience and occasion.

3. Provides supporting material (including electronic and non-electronic presentational aids) appropriate for the audience and occasion.

4. Uses an organizational pattern appropriate to the topic, audience, occasion, and purpose.

5 Uses language appropriate to the audience and occasion.

6. Uses vocal variety in rate, pitch, \& intensity (volume) to heighten and maintain interest appropriate to the audience \& occasion.

7. Uses pronunciation, grammar, \& articulation appropriate to the audience and occasion.

8. Uses physical behaviors that support the verbal message. 


\section{Skills}

Students enhanced their skills (and knowledge) by researching, developing, and presenting a live webinar or Web conference to an online, geo-dispersed audience. In this assignment, the skills competency was addressed by allowing students to present their speeches using any virtual platforms to which they had free and easy access. To clarify, skills development included presentations to both synchronous (i.e., live online) audiences composed of other students, and an asynchronous audience in the form of recorded speeches submitted to the course instructors.

\section{Feedback and Assessment in Our Course}

Throughout this online course, speeches were evaluated and feedback was provided using NCA's eight competencies, but with specific attention to the nonverbal behaviors identified in the eighth competency but applied to the digital environment. Instructor feedback included guidance related to eye contact, gestures, and the surrounding environment, to name a few. Also, in keeping with Fink's (2005) suggestion of educative assessment, interaction with the instructor and feedback are important. At the midpoint in the course, an assignment was included for a one-on-one virtual meeting with the instructors, during which students discussed their strengths and areas for improvement in subsequent speeches. This meeting was a rewarding experience and enhanced the student-instructor relationship and fostered a sense of rapport. Similarly, student feedback gathered at the conclusion of the course revealed a desire for additional student-to-student interactions and more opportunities to view other students' speeches and offer feedback.

\section{Conclusion}

The goal of this reflection essay was to reframe disciplinary dialogue about teaching public speaking online by encouraging instructors to view teaching this course not as a problem, but as an opportunity. It is precisely those instructors in the Communication discipline with an interest in public speaking instruction who should respond informedly to this pedagogical challenge. Specifically, we recommended designing and developing this important basic course using Fink's (2005) Integrated Course Design model that calls for examining four components: (a) situational factors, (b) learning goals, (c) teaching and learning activities, and (d) feedback and assessment. Given the popularity of online courses, the responsibility for educating an orally literate society still falls to scholars and instructors in the Communication discipline.

\section{References}

Allen, T. H. (2006). Is the rush to provide on-line instruction setting our students up for failure? Communication Education, 55, 122-126. doi:10.1080/03634520500343418

Beebe, S. A., \& Mottet, T. P. (2009). Students and instructors. In W. F. Eadie (Ed.), 21st century communication: A reference handbook (pp. 349-357). Thousand Oaks, CA: Sage.

Corum, E. E. (2013). On teaching public speaking online. Spectra, 49(1), 20.

Fink, L. (2005, August). A self-directed guide to designing courses for significant learning. Retrieved from https://www.deefinkandassociates.com/GuidetoCourseDesignAug05.pdf

Hunt, A. W., III. (2012). Why I am not going to teach public speaking online. Explorations in Media Ecology, 11(2), 163. 
Morreale, S. (2015). Instructional communication competence in higher education. In A. F. Hannawa \& B. H. Spitzberg (Eds.), Handbooks of communication science: Communication competence (Vol. 22, pp. 449-476). Berlin, Germany: DeGruyter Mouton.

Morreale, S., Moore, M., Surges-Tatum, D., \& Webster, L. (2007). The competent speaker speech evaluation program (2nd ed.). Washington, DC: National Communication Association.

Morreale, S. P., Myers, S. A., Backlund, P. M., \& Simonds, C. J. (2015). Study IX of the basic communication course at two- and four-year US colleges and universities: A re-examination of our discipline's "front porch." Communication Education, 65, 338-355. doi:10.1080/03634523.2015.1073339

Schwartzman, R. (2007). Refining the question: How can online instruction maximize opportunities for all students? Communication Education, 56, 113-117. doi:10.1080/03634520601009728

Spitzberg, B. H. (2000). What is good communication? Journal of the Association for Communication Administration, 29, 103-119.

Ward, S. M. (2016). It's not the same thing: Considering a path forward for teaching public speaking online. Review of Communication, 16, 222-235. doi:10.1080/15358593.2016.1187458

Westwick, J. N., Hunter, K. M., \& Haleta, L. L. (2015). Shaking in their digital boots: Anxiety and competence in the online basic public speaking course. Basic Communication Course Annual, 27, 43-77. 